\title{
Feminine in Action
}

\author{
Felisa Roldan
}

\author{
PSYCHOTHERAPIST, WeLLINGTON
}

\begin{abstract}
"The feminine" is a philosophy, a style, a value system, which is at the centre of the way I work as a psychotherapist. In this paper I wish to share the practical applications of this approach in a group therapy setting with young women aged 16 to 23 . As a psychotherapist and psychiatrist, I am well versed in the more masculine value system. I use concepts like transference and counter-transference, defence mechanisms, diagnostic criteria, and all the other ways of understanding what is happening in our therapeutic experience. Moreover, I teach a lot of these concepts. I am therefore not intending to devalue the usefulness of these theoretical concepts. It is much harder to define and bring into dialogue the values of the feminine. It is not a measurable concept that can be packaged in skills training or researched with placebo control studies and published in a scientific paper. In spite of that, I believe it is an important concept to introduce and to discuss in the psychotherapy world. In this paper I describe some clinical applications of the concept of the feminine in order to demonstrate its value to our work.
\end{abstract}

\section{Whakarāpopotonga}

He rapunga whakaaro, he kōpuratanga, he whakatakotoranga uara te uha, à, pokapù tēnei ki te āhua o tāku mahi i aku mahi kaiwhakaora hinengaro. E hiahia ana au ki te tohatoha i ngā mahi haratau o tēnei momo mahi ki waenga i tētahi haumanau awheawhenga taitamāhine mai i te 16 ki te 23 nei ngā tau. Mai i ōku kaiwhakaora hinengaro, rata mate hinengaro, e tino mātau ana au ki te whakatakotoranga uara tānetanga. Mahia ai e au ngā tū āhua ariā pēnei i te whakawhiti me te awherangi whakawhiti, ngā momo waonga, te paearu whakatau mate, me ērā atu anō o ngā mātauranga whakamārama kei te aha ngā whakanekenekehanga o ō tātou wheako haumanu. Otirā, ākonga ai e au te maha o ènei ariā, ā, me pēhea hoki e taea ai te whakaiti, te painga o ēnei ariā. He uaua kē atu te tautuhi uara taitamāhine ka whakauru mai ai ki ngā kōrero. Ehara i te ariā inea ka taea nei te tākai whakangungunga pukenga rangahaua rānei ki tētahi akomanga whakahaere tohipa ka tā ai ki tētahi pepa pūtaiao. Ahakoa tērā, e whakapono ana au he ariā whai tikanga hei whakamōhio hei aromatawai i roto i te ao whakaoranga hinengaro. E whakamārama ana au i ètahi ariā mahinga haumanu o te taitamāhine hai whakaatu i ōna uara ki ā tātou mahi.

Roldan, F. (2015). Feminine in action. Ata: Journal of Psychotherapy Aotearoa New Zealand, 19(1), 35-47. DOI:10.9791/ajpanz.2015.04 @ New Zealand Association of Psychotherapists Inc. 
Keywords: feminine; intuition; mindfulness; self-compassion; presence; right/left brain; story-telling

In a previous paper on "the feminine" (Roldan, 2005) I concentrated on defining what is meant by this concept so I will only describe it briefly here before proceeding to share how I have, since that time, put my thoughts into practice in the context of group therapy.

The slow change from polytheism to monotheism contributed to the loss of the goddesses that kept alive the feminine principle. Ancient cultures ruled by feminine archetypes lasted about 25,000 years as compared with 3,000-4,000 years of masculine sovereignty (Meador, 1992). The original pagan Germanic and Celtic religions had many cults of Mother Earth and other nature goddesses but Christian civilisation slowly repressed this element.

Other events such as the witch persecution added to the disconnection from this archetype. Finally, the birth of science in Western culture emphasised the predominance of masculine thought processes. Science set out to look at the world in terms of "cause and effect" in order to gain mastery over our surroundings and progressively became the only lens through which one could supposedly perceive reality.

Jung wrote "the loss of an archetype gives rise to that frightful discontent in our culture" (1953, para. 141). This is exactly the case with the feminine archetype. Its burial has taken with it important values and psychic experiences, leaving dissatisfaction and lack of balance in our lives. Jung's concept of anima, which has been further developed by post-Jungian analysts, is similar to the concept of the feminine which I am trying to describe.Unfortunately, Freudian psychoanalysis has not added any depth to this subject. Von Franz pointed this out: "Freud had very little recognition of the feminine element and therefore always explained it as sex" (1996, p. 85).

American Jungian analyst Nancy Qualls-Corbett summarised some of the implications of the loss of the feminine:

When the divine feminine, the goddess, is no longer revered, social and psychic structures become overmechanized, overpolitized, overmilitarized. Thinking, judgement and rationality become the ruling factors. The needs of relatedness, feeding, caring or attending to nature go unheeded. There is no balance, no harmony, neither within oneself nor in the external world. With the disregard of the archetypal image so related to passionate love, a splitting off of values, a onesidedness, occurs in the psyche. As a result, we are sadly crippled in our search for wholeness and health. (Qualls-Corbett, 1988, p.16)

Similarly, in her clinical work, Jungian analyst Dr Rachel Hillel found that repression of the feminine is a central theme that women need to explore: "Women's introjected masculine values prevent their true liberation. Women's psychological work entails becoming aware of this internal possession so that they can free themselves from the identification with the role of the father's daughter. This is made harder in a culture that promotes masculine principles" (1997, p. 65).

The educational system is a good example of the predominance of the masculine value 
system. Science is encouraged over and above the study of humanities i.e. philosophy, mythology, religion, poetry, etc. Humanities, however, bring us closer to a person's internal experiences and closer to the feminine. Why are these subjects not part of psychotherapy training? Without the feminine in our lives we do not have a centre, a compass to navigate the complexities of life. Without the feminine, life loses the juice of imagination and reflection and it becomes one-dimensional and eventually dull. Jung makes this quite clear:

After the middle of life, however, permanent loss of the anima means a diminution of vitality, of flexibility, and of human kindness. The result, as a rule, is premature rigidity, crustiness, stereotypy, fanatical one-sidedness, obstinacy, pedantry, or else resignation, weariness, sloppiness, irresponsibility, and finally a childish ramollissement with a tendency to alcohol. (Jung, 1953, para.147)

\section{Defining the Feminine}

I will look at three aspects of the feminine; thought, feeling, and instinct.

Feminine thought does not start with the examination of a detail but with the contemplation of the whole. It makes connections in a symbolic and inductive manner. For this reason poetry, images, metaphor, and paradox are better methods to explore this style of thought. Jung was the first to understand the great importance of the illogical and inductive process and its relationship with the symbolic dimensions. Unlike masculine thought which is more interested in analysing and classifying in a more logical and deductive fashion, feminine thought creates connections that are not so clear to the logical mind. For this reason it has often been judged to be too close to the magical realm and dismissed. The feminine remains centred and still around feelings. It has a more contemplative disposition in contrast with the masculine which is more inclined to find a solution or come up with a plan of action.

Feminine feeling, on the other hand, witnesses a feeling, receives it and in fully doing so can reveal a deeper meaning to it.

Feminine instinct presents two aspects: the maternal sphere and the feminine sexual sphere.

The maternal sphere has a desire to protect, nourish, and nurture. Like other female animals, genetically prepared to be responsible for lives other than their own, women are quick learners and keen observers and can achieve high levels of understanding of the human condition. This is sometimes called "feminine intuition". Suffering is also part of the feminine. In the not so distant past childbirth was followed by death. Aztec women who died in childbirth were equated with warriors who died in battle. Suffering is also necessary for increased awareness and development of the personality. The feminine knows how much effort goes into the creation of a life and is therefore less easily persuaded by the we/ they dichotomy, and more prone to sympathise with the basic humanness and vulnerability of other human beings. Finally, the feminine is closer to the natural cycles which are alive in a woman's body on a regular basis.

The other aspect is the feminine sexual sphere which has suffered repression over the years. As Hillel wrote: 
The harlot archetypal image, a feminine ancient Goddess, was reduced in its entirety by collective Judeo-Christian morality. It was considered an exclusively negative, lowly, and inferior matrix, devoid of spirituality. The Goddess represented by the harlot archetypal image was identified solely with the prostitute polarity. The denial of the Goddess' divinity brought about an annihilation of the sacred priestess polarity. (Hillel, 1997, p. 112)

Hillel added: “The feminine's essential meaning to the human psyche is reduced when the sacredness of the vulva is unacknowledged and denied" (1997, p.120).

Nancy Qualls-Corbett expressed the same sentiment: "No matter what her name, the love goddess is related to the earth, the body, to passion, sexuality and fertility. She is the moving, transforming, mystical power of love which unites the human element with the divine" (Qualls-Corbett, 1988, p.16).

Consciousness of feminine nature begins in deep appreciation of, and caring devotion to, the body. Women are closer to the natural rhythms by the fact of their physiological cycles. The attack on the body that we see in the rise of anorexia nervosa in adolescents gives room for thought as to the metaphorical attack of the feminine given that this illness often begins so close to the time when a woman begins to menstruate. Generally, however, the attack tends to be more subtle but no less damaging.

\section{Defining the Feminine in Contrast with the Masculine}

Looking at the contrast between the two paradigms can give us another understanding of the feminine. The following are some values of the two principles:

$\begin{array}{ll}\text { Masculine } & \text { Feminine } \\ \text { Linear } & \text { Cyclical } \\ \text { Analytical } & \text { Strategic } \\ \text { Mental } & \text { Feeling } \\ \text { Fast/quick } & \text { Slow } \\ \text { Light } & \text { Dark } \\ \text { Active } & \text { Receptive } \\ \text { Either/or } & \text { Both/and } \\ \text { Doing } & \text { Being } \\ \text { Outcome oriented } & \text { Process oriented } \\ \text { External focus } & \text { Internal focus } \\ \text { Competitive } & \text { Collaborative } \\ \text { Rational } & \text { Intuitive }\end{array}$

Marion Woodman (1998), a Jungian psychotherapist who has written and worked with this concept for years defines the feminine in simple terms:

Presence

Attending to the process 


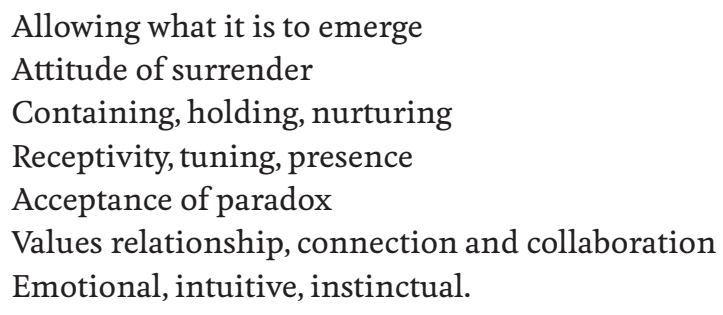

Hopefully, I am creating a picture of the feminine as a different paradigm, a different value system, and a different perspective.

\section{Setting the Scene}

I tried to bring this idea of the feminine into the philosophy of my workplace which is an eating disorder (ED) unit. I believe, however, that this can be put in practice in any setting including in individual work with clients. I have worked in the ED service for eight years and for most of my initial years I concentrated on building good relationships with all my colleagues; nurses, psychotherapist, psychologists, administrator, and support workers. I shared my ideas with them and by the time I started facilitating a group enough people supported this way of working. I also developed strong ties with the other therapists running groups at our service. This meant that we met regularly and a number of the themes started to flow from one group to another giving more strength to what we were doing.

Looking back, one may wonder why I did not start the group work soon after I arrived in the service given that by then I had worked on the feminine for quite a while. However, this is part and parcel of the feminine. Building supportive relationships and a safe network is a first building block. This acts as a nest that contains the work that we continue facilitating in the groups. It "cradles", extends, and protects this work.

\section{Initial Phase}

I was tentative, especially at the beginning, as I was not sure how to introduce the idea of the feminine to this particular group of clients. Initially, I introduced a practice called "mindfulness and self-compassion" (MSC) at the beginning of each group to facilitate receptivity and calm the mind. Clients found it hard at first yet they were willing to persevere and the quality of their interactions after the practice clearly deepened. I explained to them the rationale for using mindfulness as well as some of the research behind it in order to interest them in the practice. I drew on Daniel Siegel's (2007) work as he has researched this area finding that mindful awareness promotes neural integration.

Mindfulness practice is about practising "presence", the capacity to be where one is in the present moment. The self-compassionate part of mindfulness increases self-nurturing as well as the capacity to hold and contain difficult experiences. This modality also promotes receptivity and acceptance without judgement. Furthermore, it involves an attitude of surrender. For all these reasons, I believed MSC could prepare our clients to connect with the feminine at a deeper level. 
I had already had a number of teaching sessions on MSC with the staff and we introduced a few minutes of MSC before our multidisciplinary team meeting as it is important to always embody what we teach. Presence is about this embodiment, which is palpable to the other and requires no words for communication.

In the second part of the client group we read stories that explored different aspects of the feminine. A number of the stories came from Anita Johnston's book Eating in the Light of the Moon (1996). Stories, myths, metaphors, and symbols are the portal to the exploration of the feminine.

Following the telling of the stories, I left the group open to free association, going with the symbols that initially attracted the women's attention. At times I would also query what they did not pay attention to. In some ways the style of inquiry was similar to working with dreams. I hoped that the metaphors and symbols of the stories would open them up to deeper meanings as this client group, like many of us, has a tendency to over-rationalise.

I also explained the difference between right- and left-brain functions and how I wanted the group to increase the functions of the right brain as the feminine principle is better represented by right-brain activity (McGilchrist, 2010). The right brain is non-verbal, sees the whole picture, and keeps global, rather than focused, attention. The right brain helps us find meaning because it can see more of the big picture.

\section{Initial Stories}

Stories and fairy tales depict the basic patterns of the human psyche. One of the first stories we read was an old Bantu folktale "The name of the tree". This is the story of the animals in the jungle trying to find out the name of a very tall tree so that they can eat from it. If they cannot discover its name they will die of hunger. The tortoise is the only animal that is capable of this task. She shows persistence, patience, and a quiet determination to achieve what she needs for herself and the rest of the animals.

In the same way, learning to know what we are really hungry for, what we are starving of, is very important for a woman with an eating disorder. Food is only a very concrete way of expressing a need for something else. It is a "red herring" that distracts us from the real hunger for something else; acceptance, love, desire, nurturance, and more.

The attitude of the tortoise is helpful in the journey of understanding oneself better. The gazelle was fast but had a bad memory so she was not much help. The elephant had a great memory but got so caught up in his abilities to memorise that he fell in a hole. The tortoise had the ability to balance her skills so, with a lot of care and a measured belief in herself, discovered the name.

We followed this theme with "The buried moon" which talks about what happens when the moon gets buried and the night-time world becomes dangerous. This story opened us to talk about the different perspective of seeing something in the light of the moon versus the light of the sun. The moon supports qualities which are closer to the feminine. We talked about how mysterious and atmospheric things appear in the light of the moon. This also led to a discussion of the feminine as the principle that values feelings, relationships, and receptivity as the diffuse light of the moon allows more reflective time. The moon has a cyclical and dynamic aspect of change and transformation which is very much like a 
woman's monthly cycles. The moon goes through a dark phase, which we viewed as a time of renewal, just as there are times in a woman's cycle when we feel more like retreating.

We also talked about night time as the quiet part of the day when we are more able to listen to what is going on inside us. This can be a difficult time if there are many unhappy memories and feelings as there is very little to distract ourselves with.

\section{Rituals}

At the start of the group, I asked the women to bring their ideas of what they wanted to do in the group. Soon enough they talked about wanting to burn some magazines with images they found offensive, such as images of very skinny women. We took this as a theme over a couple of groups and looked at the power of transformation through the fire and the space left for something new to grow. The women looked at other attitudes or ideas they wished to let go of and we incorporated this theme during our mindfulness through visualisations drawing on the theme of fire.

The fire in which we burnt the images occurred during a very windy Wellington day which gave the ritual some power indeed. We invited other staff from the service and some of them also burnt papers or letters that they wanted to let go of.

Soon after this I went to Hawaii to the Big Island for an eating disorder workshop titled "Tending the feminine". During this visit, the volcano on the island was active. The local people talked with reverence about Pele, the Goddess of Fire. They did not seemed annoyed about all the detours we had to take because the lava had cut off a number of roads, viewing the eruption as meaningful rather than inconvenient. "Pele was here before we came," some of them said, "so we just need to give her the space she needs."

Following the fire rituals clients talked about wanting to plant a seed so from the ashes of the fire we moved to planting seeds together. This provided helpful symbolism to look at nurturing a plant, what it needs to grow, and how long it takes for a seed to grow, building parallels with their own nurturing. Some clients found the idea of nurturing quite foreign, most probably because they had not internalised a good enough nurturing experience or/ and because of their focus on pleasing the other and fitting in.

Anita Johnston (1996) provided another story for the theme of nurturance "The princess and the Goddess". In this story a princess loses her wise and loving mother. The princess goes through a strong grieving process in which her father feels unable to help her. She stops going to the forest because of her sadness. Time passes and she begins to slowly pretend that she is fine by shutting down her feelings. However, on her 21st birthday she begins to feel different. She starts to go out into the forest as she used to, the colours look brighter, and she starts hearing her mother's voice coming from the ocean. Her mother's voice tells the princess that she is everywhere: "I am the sea. I am the flowers. I am the stars that shine at night. I am your breath. I am your tears. I am your mother and I will never leave you."

Good mothering is about containing, being receptive, holding, and encouraging. This story opened up conversations about how important it is to find our own mother inside ourselves. Conscious mothering is about becoming a container for ourselves and maybe even for another. The internal mother encourages us to be open and allowing of our feelings, 
containing them and allowing us to find wisdom and guidance from them, just like a mother would do with a child.

We used mindfulness to learn to stay with feelings without becoming overwhelmed. Mindfulness is an antidote to over-identification with suffering. After we had practised it for a while we were able to find that balance between over-identifying at one extreme and suppressing the feeling at the other.

My collaborative style continued throughout my facilitation of the group. I wanted to hear the needs of the women and allowed for constant fluid feedback from the group so that they could feel ownership of the process. This is also in keeping with the principle of collaboration which is very much a feminine value.

\section{The Ugly Duckling}

The next story that seemed relevant to the mood of the group was "The ugly duckling" by Hans Christian Andersen. Most women in the group identified with the ugly duckling and talked about feeling like outsiders, always different to their families or different to friends. Stories of not feeling accepted or feeling bullied in different contexts were told.

At the same time I noticed a very strong self-critic appearing in these conversations. We explored the self-critic and I decided to introduce the concept of self-compassion. Using the Gestalt "chair technique" we put the self-critic and the compassionate self in dialogue with each other. Often clients needed help from other members of the group when trying to speak from the self-compassionate chair. Clients found it much easier to speak from the self-compassionate chair for another member of the group than for themselves. The harshness of the self-critic became the most important theme, as well as the very undeveloped compassionate self.

\section{Goddesses}

At this stage, I suggested looking at different goddesses from Greek times to expand our idea of the feminine beyond what we had been exposed to through the media. I used stories from a Jungian analyst Jean Shinoda Bolen (1983), introducing seven goddesses: Aphrodite, Artemis, Persephone, Demeter, Hera, Athena, and Hestia. When I asked the group who they were most drawn to they chose Demeter/Persephone so we proceeded to explore the rich content of this myth.

The women were taken by the sudden descent of Persephone into the underworld and began to talk about their experience of going down into their own underworlds. They talked about how hard it was to be snatched into the underworld, in their case by their eating disorder. They noticed Persephone's naivety and viewed Demeter as quite a strong character and mother but they thought that Persephone was a bit dependent on her. Perhaps, they thought, Persephone learnt from going down to the underworld and facing this difficult experience on her own.

Some of the women talked about their mothers in an idealised manner. Idealisation makes it harder for the young woman to separate from her mother; it is as if the young woman still has the view of their mother from a child's omnipotent perspective. Other 
clients felt quite different to their mothers and did not feel accepted by them, often feeling as if they were a disappointment to them.

The women's relationships with their mothers and issues related to separating from them became a very alive theme. Part of this task involves sorting out in which ways we are like our mothers and in which ways we differ.

Persephone eats the pomegranate seed which means she had to spend one-third of each year in the underworld with Hades. After a lot of discussion the group came to view the seeds as the wisdom that Persephone had gathered from the underworld. Suffering makes us mature and wise, and it changes us forever. In our last group on this subject we shared some pomegranate seeds to close the work on this story.

The next goddess to attract the group attention was Aphrodite. However, this time they did not identify with her: they struggled to connect with the sensuality, personal magnetism, and passion of this goddess. We spent a couple of groups looking at the four tasks that Aphrodite sets for Psyche as they are the tasks required in the psychic development of the feminine:

1. Sorting the seeds: clarity and intuition.

2. Acquiring the Golden Fleece: gaining power and remaining compassionate.

3. Filling the crystal flask with water: finding a container and some healthy emotional distance. 4. Descent to the underworld: developing courage and determination.

The group talked about sorting out what is important in their lives and about containing their feelings by acknowledging them instead of dismissing them, yet without being overwhelmed by them.

\section{Intuition and Wisdom}

The next theme that came up from the group was the idea of intuition or internal wisdom. This came from the goddess stories and also from doing the chair work. I noticed and commented on the inherent wisdom that seemed to come whenever they talked from their self-compassionate selves.

As our art therapist Irena Stenner was interested in developing the idea of the self-critic and the compassionate self through artwork clients painted masks to represent both selves during art therapy and continued creating them in their own time. The painting of the two masks occurred over some weeks whilst we were also exploring the theme of intuition and inner wisdom. The self-critic masks were mostly black and almost all of them had something covering the mouth, a cloth or even a thread.

Using the masks, the women were encouraged to voice as much as possible the messages from the self-critic side and from the compassionate side. Then two other members in the group put on the client's masks and had a dialogue with the group. Clients were able to talk about the self-critic messages after a few sessions of warming up. Often, however, they found it very hard to find words for the self-compassionate side. Some of them also hesitated to let their masks be used by the other participants.

Listening to the content of their critics one could see how much society has emphasised 
that women's worth depends on their looks and their performance. The intense harshness of the self-critic did surprise me at times even though I expected it. It was powerful for the women to see and hear their internal dialogue out in the external world. Somehow it was not a secret anymore and the similarities amongst the self-critics helped them with the feelings of isolation and the shame that was often palpable in the group.

We realised that this work was closely linked with their intuition and their inner wisdom; intuition actually means "inner teacher". We talked about intuition as a knowing that comes from beyond the physical senses. It is not simply a mental process but one which involves our bodies and our hearts, and involves a certain active receptivity. In our society, and particularly our education system, we are too focused on looking for knowledge outside ourselves and we have been trained to distrust our inherent knowledge. Often our intuitive knowledge has not been valued or, even worse, been ridiculed. Clarissa Pinkola Estes wrote: "There is no greater blessing a mother can give a daughter than a reliable sense of the veracity of her own intuition" (1992, p. 89).

My inclination was not to try to understand why the women's trust in their intuition had been buried but to help them as much as possible to uncover this great treasure. If they could connect with their internal wisdom and intuition, their lives could be much richer and the self-critic would take its rightful place rather than continue to be so powerful. I encouraged the women to bring images that they felt represented intuition. We also used visualisation to enhance their connection with wisdom.

Finally, we read a Russian story “The lute player" (Johnston, 1996) which is about a queen who had to rely solely on her intuition to survive a number or trials and tribulations. Initially, she had to wait until it became clear what she needed to do to save the king and then she had to trust her intuition and find the courage to follow through.

How do we know that what we listen to is our own intuition? How do we listen, reflect, and trust it when we have not had the experience of being mirrored or valued when we verbalised it? Intuition is closely connected to our truth, our essence, and our vision. These young women said that this was the very first time they had talked about this topic. This was the very beginning of starting to uncover a treasure buried deep in their psyche. Some clients shared stories of how they constantly overrode their intuition or inner guidance to conform to what they believe is acceptable. Often they have done this from a very early age, possibly even pre-verbally.

An adolescent is at a developmental crossroads and needs to rely more and more on her or his internal guidance. She needs discernment to choose amongst a number of possibilities. If, however, she does not have this intuitive guidance, she can become overwhelmed, ill equipped, and fearful to take the next step, often resulting in symptomatology. Of course, this is also the case at other times of great change like menopause for women and during midlife in general for men.

\section{Our Truth}

Hans Christian Andersen's “The Emperor's New Clothes” felt like a good way to explore further how we connect with our truth even if other people do not agree with us. Most of the women talked about going along with other people for fear of not being accepted or out of 
fear of conflict. They also did not believe their opinions were as valuable as others' opinions.

None of the women had ever heard of this fairytale before, in fact, a lot of the stories I told them were foreign to them. I wondered what has been lost in this generation through the lack of exposure to these classic tales. Stories bring down wisdom from the generations that ground us and give us our bearings.

Not knowing our truth means we do not know who we are, emptiness sets in and loneliness comes with it. My clients often talked about this feeling of emptiness that they dread and about their difficulties in having a real identity and knowing who they really are. "As children, when we felt the dissonance between society's expectations and our inner wisdom and questioned society, we were told to adapt to what was expected ... we confused love with self-sacrifice ... we ignored our feelings in favour of obedience.... Alongside anger, a feeling of 'loss of self' results from many years of self-sacrifice” (Kumar, 2011, Chapter 6, para.10).

I asked the group what fairytale they remembered best from their childhood. One of the most remembered was "Red Riding Hood" so we read and discussed it during two groups. First we read the best known version which was written by the Grimm Brothers. We looked at each character as a part of ourselves which we may have fully developed or be in the process of doing so. Red Riding Hood is portrayed as innocent, open, playful, and trusting. These qualities are very valuable and we do not want to lose them when we grow up. However, we have to develop other parts of ourselves to protect and guide this more vulnerable part.

The mother is portrayed as a sensible, mature, earthy woman who would not be fooled by the wolf.

The wolf is ravenous, primitive, and drifty: he follows his desires. This can also be a part of us that we keep in check much of the time. Although this part can cause us trouble if not guided by other more mature parts, we do not want to lose it totally as it gives us a desire for life. A couple of the clients saw the wolf as the "eating disorder" in that it behaves in a sneaky way and is experienced as being very forceful when it wants to achieve its goal.

Grandmother is vulnerable, however, she is also wise and compassionate.

Red Riding Hood comes out of the wolf's stomach transformed and, with guidance from the older parts of herself, gains incredible wisdom. She is transformed by this painful experience.

In the second version of this story, the wolf does not eat Red Riding Hood. After a while she becomes suspicious of him and trusts her instincts enough to save herself. In this version the girl is an orphan so it makes sense that she has to rely on her intuition. This version tied very well with our work on intuition as it can be a lifesaver.

We continued with more stories and fairytales and sometimes read our own and others' poems. At times, I brought stories that resonated with the themes raised in the previous groups. On other occasions clients suggested particular stories that were meaningful to them. We always had time at the start of the group to practise mindfulness and selfcompassion. Some groups were dedicated to attending to the process of the group. This was especially relevant when there was conflict or general unhappiness between members of the group. 


\section{Conclusions}

My ideas are not put together in a well-packaged programme or formula that can be applied by the book as that would go against the idea of the feminine. These are, I realise, initial, clumsy, and unsophisticated attempts at uncovering the feminine. But I believe that my ideas could be applied to other settings as long as differences were allowed for, for example, the stories could be adapted to other themes. This is not about learning a new skill. It is about uncovering, allowing, and trusting our own intuition, our own wisdom that we so very often undervalue in a world which is so focused on knowledge gained from external sources.

In my current area of work, women comprise $90 \%$ of my clients, however, I believe that men need to connect with the feminine as much as women do.

I have not written about the marriage and balance of the feminine and the masculine which, after all, is our aim. The writing of this paper was an attempt at using my rational mind to express and communicate an experience that is often buried, unseen or undervalued. When we value feminine as much as masculine principles and marry them inside ourselves, we will embody more wholeness as therapists. The concept of the marriage of feminine and masculine is an ancient concept. For example in Chinese culture it is represented by the Yin (feminine) and the Yang (masculine) and in India by Shiva (masculine) and Shakhty (feminine).

Because we live in a culture that values masculine principles more, as therapists we need to maintain constant awareness in order not to collude with cultural bias.

One of my main motivations to share this work was to connect with other psychotherapists who are already working in this manner in the hope that they could provide me with feedback from which I could further develop my ideas.

\section{Acknowledgement}

This article is dedicated to Moana-O-Hinerangi and Pamela Wilson.

\section{References}

Bolen, J.S. (1983). Goddesses in everywoman: A new psychology of women. New York, NY: Harper \& Row.

Estés, C. P. (1992). Women who run with the wolves. New York, NY: Ballantine Books.

Germer, C. (2009). The mindful path to self-compassion. New York, NY: Guildford Press.

Gilbert, P. (2013). Mindful compassion. London, UK: Robinson Publishing.

Hillel, R. (1997). The redemption of the feminine erotic soul. York Beach, NY: Nicolas-Hays.

Johnston, A. (1996). Eating in the light of the moon. Carlsbad, CA: Gurze Books.

Jung, C. G. (1953). The archetypes and the collective unconscious. In The collected works of C. G.

Jung (Part 1, Vol. 9; R. F. C. Hull, Trans.). Princeton, NJ: Princeton University Press.

Kumar R. (2011). Becoming real: Harnessing the power of menopause for health and success. Pewaukee,

WI: Medial Press.

Meador, B. (1992). Uncursing the dark. Wilmington, IL: Chiron.

McGilchrist, I. (2010). The master and his emissary. New Haven, CT: Yale University Press.

Neff, K. (2011). Self-compassion. New York, NY: William Morrow. 
Qualls-Corbett, N. (1988). The sacred prostitute: Eternal aspects of the feminine. Toronto, Canada: University of Toronto Press Inc.

Roldan, F. (2005). The feminine. Forum The Journal of The New Zealand Association of Psychotherapists, 96-102.

Siegel, J. (2007). The mindful brain: Reflection and attunement in the cultivation of well-being (2nd ed.). New York, NY: W. W. Norton.

Valcarenghi, M.(1997). Relationships, transforming archetypes. York Beach, ME: Nicolas-Hays.

Von Franz, M.-L. (1996). The interpretation of fairy tales. Boston, MA: Shambhala.

Woodman, M. (Speaker). (1998). Sitting by the well. [Cassette Recording]. Boulder, CO: Sounds True Audio.

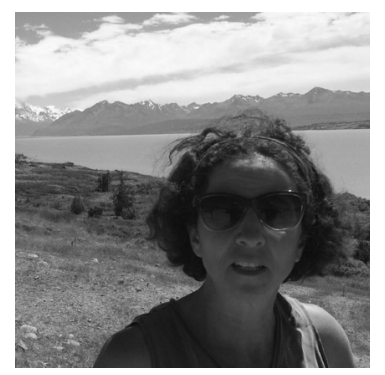

Felisa Roldan undertook medical training in Spain and moved to the UK in 1988 . In 1990, she started her training in psychiatry and became a member of the Royal College of Psychiatrists in 1994. During her final year in the UK, she worked in a psychotherapy unit where she first started training in psychotherapy. Her supervisor was a Kleinian analyst. In 1995, she moved to New Zealand and worked in Ashburn Hall therapeutic community for a year to continue training in psychotherapy. She also formally trained as a Gestalt therapist, obtaining her diploma in 1999. Between March and November 2000, she attended weekly seminars on Jungian Analytic Psychology run by the Albany Trust, and she continues to attend a Jungian reading group that was started over a year ago. She has been registered with the Psychotherapist Board of Aotearoa New Zealand since its creation. Felisa is currently working as a consultant psychiatrist for Central Regional Eating Disorder Service. She has been in this position for more than eight years. Since 2005 she has worked for the Regional Australian and New Zealand College of Psychiatrists as a psychotherapy coordinator, providing advice and education in the delivery of psychotherapy to registrars and supervisors in the training scheme. Contact details: felisa@clear.net.nz . 